\title{
EFEITO DE TRÊS PROCESSOS DE VINIFICAÇÃO SOBRE A COMPOSIÇÃO QUÍMICA E A QUALIDADE DO VINHO CABERNET FRANC ${ }^{1}$
}

\author{
LUIZ ANTENOR RIZZON² ${ }^{2}$ ALBERTO MIELE ${ }^{3}$, JÚLIO MENEGUZZO ${ }^{4}$ e MAURO CELSO ZANUZ ${ }^{5}$
}

\begin{abstract}
RESUMO - Foram avaliados os efeitos de três processos de vinificação sobre a composição química e a qualidade do vinho Cabernet Franc, nas safras de 1987 a 1990. As vinificações foram realizadas em escala industrial, pelos processos clássico, de termovinificação e de maceração carbônica. Avaliaramse teor alcoólico, acidez total, açúcares redutores, cinzas, extrato seco, compostos fenólicos e voláteis e elementos minerais. Procedeu-se, também, à análise sensorial dos vinhos. Os resultados foram submetidos à análise de componentes principais (ACP) e à análise de variância, sendo que os três primeiros eixos explicaram $68,2 \%$ da variação total. Através da ACP, foi possível separar os vinhos de maceração carbônica dos outros dois processos de vinificação. As variáveis que apresentaram maior efeito na variação foram os álcoois superiores, os cátions e os compostos fenólicos. A avaliação sensorial mostrou que a maceração carbônica originou vinhos leves e com menor intensidade de cor, e a termovinificação e a vinificação clássica originaram vinhos com mais corpo, melhor qualidade e equilíbrio gustativo e maior tipicidade varietal.
\end{abstract}

Termos para indexação: enologia, maceração carbônica, termovinificação.

\section{EFFECT OF THREE PROCESSES OF VINIFICATION ON CHEMICAL COMPOSITION AND QUALITY OF CABERNET FRANC WINE}

\begin{abstract}
The effects of three processes of vinification on chemical composition and quality of Cabernet Franc wine were evaluated from the 1987 to the 1990 vintages. The vinifications were made in an industrial scale by the following processes: conventional vinification, thermovinification and carbonic maceration. The analyses performed were alcohol, total acidity, reducing sugar, ash, dry extract, phenolic and volatile compounds and mineral elements. The quality was evaluated by sensory analysis. Data were submitted to principal component analysis (PCA) and to analysis of variance, where the three first axes explained $68.2 \%$ of the total variation. The PCA permitted to separate the wines of carbonic maceration from the other two vinification processes. The variables presenting important variation effect were the higher alcohols, cations and phenolic compounds. The sensory evaluation showed that carbonic maceration originated lighter wines with lower color intensity; the thermovinification and the conventional vinification originated wines with better body, better quality and gustative balance and with higher varietal characteristic.
\end{abstract}

Index terms: enology, carbonic maceration, thermovinification.

\section{INTRODUÇÃO}

Vinhos tintos de elevada qualidade somente são obtidos em regiões vitícolas específicas, onde a uva

\footnotetext{
${ }^{1}$ Aceito para publicação em 15 de outubro de 1998.

${ }^{2}$ Eng. Agr., Dr., Embrapa-Centro Nacional de Pesquisa de Uva e Vinho (CNPUV), Caixa Postal 130, CEP 95700-000 Bento Gonçalves, RS. E-mail: rizzon@cnpuv.embrapa.br

${ }^{3}$ Eng. Agr., Dr., Embrapa-CNPUV. Bolsista do CNPq. E-mail: miele@cnpuv.embrapa.br

${ }^{4}$ Eng. Agr., Embrapa-CNPUV.

${ }^{5}$ Eng. Agr., M.Sc., Embrapa-CNPUV. E-mail: zanuz@cnpuv.embrapa.br
}

atinge maturação e sanidade adequadas. Os compostos fenólicos são os constituintes que melhor diferenciam qualitativamente os vinhos tintos, pois interferem na cor, no extrato seco e, conseqüentemente, na qualidade desses vinhos (Ribéreau-Gayon \& Glories, 1986). No Brasil, onde é produzido um volume considerável de vinho tinto, observa-se, atualmente, um potencial para a elaboração de vinhos tintos jovens. A maceração carbônica e a termovinificação são processos tecnológicos alternativos para a elaboração desses vinhos. Além disso, possibilitam a obtenção de produtos com características 
sensoriais diferenciadas em relação aos elaborados pelo processo clássico.

Na elaboração do vinho tinto pelo processo clássico, a fermentação alcoólica e a maceração ocorrem simultaneamente. Nessa fase, os constituintes da parte sólida da uva, principalmente da película, passam para o mosto através dos fenômenos de dissolução e de difusão (Ubigli, 1988).

A utilização do processo de maceração carbônica é recomendável quando se dispõe de uva inteira, sadia, com baixo teor de tanino e elevada concentração de ácido málico, açúcar e antocianinas (Usseglio-Tomasset, 1986). Em condições anaeróbicas, a maceração carbônica transmite aos vinhos algumas características diferenciadas, dadas as reações enzimáticas que ocorrem na baga intacta (André et al., 1967; Flanzy et al., 1970; Arfelli, 1990). Nesse processo, a baga sofre uma fermentação intracelular, em que o ácido málico, principal composto metabolizado, é transformado em álcool etílico e em outras substâncias (Càstino, 1984; Versini et al., 1984; Ubigli, 1986; Spagnolli, 1987; Villa, 1988).

A termovinificação é um processo indicado para uvas tintas com pouca matéria corante e sanidade deficiente (Ribéreau-Gayon et al., 1976; Peruzzi, 1991). Consiste principalmente na extração, pelo aquecimento da uva, das antocianinas e de outros compostos fenólicos responsáveis pela coloração dos vinhos tintos. O processo deve ser conduzido de modo a inativar as enzimas oxidativas, preservando aquelas com atividades proteolíticas e pectinolíticas (Wagener, 1981).

Esses processos de vinificação podem contribuir para melhorar a qualidade dos vinhos finos brasileiros.

Com esse objetivo, estudaram-se os efeitos da vinificação clássica, da maceração carbônica e da termovinificação, na composição química e na qualidade do vinho Cabernet Franc.

\section{MATERIAL E MÉTODOS}

O trabalho foi realizado na Embrapa-Centro Nacional de Pesquisa de Uva e Vinho, localizada em Bento Gonçalves, RS.
A uva Cabernet Franc foi colhida de 1987 a 1990, na Fepagro-Estação Experimental de Caxias do Sul, localizada em Fazenda Souza, Caxias do Sul. A colheita foi manual, e o transporte efetuado em caixas de plástico com capacidade de $20 \mathrm{~kg}$.

As vinificações foram realizadas em escala industrial, com $3.000 \mathrm{~kg}$ de uva em cada processo de vinificação. Não foi efetuada chaptalização do mosto em nenhuma safra vitícola.

No processo de vinificação clássica, a uva foi separada da ráquis e esmagada. O período de maceração foi de cinco dias, com duas remontagens diárias, com temperatura entre $25^{\circ} \mathrm{C}$ e $28^{\circ} \mathrm{C}$. A seguir, o mosto foi separado da parte sólida da uva e colocado em outro recipiente equipado com uma válvula. O desdobramento do ácido málico pelas bactérias lácticas aconteceu espontaneamente e foi acompanhado por cromatografia de papel.

No processo de maceração carbônica, a uva foi colocada, o mais intacta possível, num recipiente de aço inoxidável com capacidade para $4.000 \mathrm{~L}$. A seguir, foi injetado dióxido de carbono no tanque, através de uma válvula, até alcançar 0,5 atm de pressão. Esta etapa da maceração carbônica durou dez dias, e a temperatura variou de $25^{\circ} \mathrm{C}$ a $30^{\circ} \mathrm{C}$. Concluída esta fase, a uva foi colocada inteira, inclusive com a ráquis, numa prensa horizontal descontínua de pratos, para separar o mosto da parte sólida. A temperatura de fermentação foi de $20^{\circ} \mathrm{C}$.

No processo de termovinificação a uva foi separada da ráquis, esmagada, aquecida a $65^{\circ} \mathrm{C}$ e colocada, por 2 horas, em um depósito de aço inoxidável equipado com mecanismo para homogeneização. A seguir, o mosto foi separado da parte sólida da uva por meio de um esgotador dinâmico e de uma prensa contínua. A fermentação alcoólica ocorreu sem a participação da parte sólida da uva e à temperatura de $20^{\circ} \mathrm{C}$. O metabolismo do ácido málico pelas bactérias lácticas ocorreu espontaneamente, logo após a fermentação alcoólica, e foi acompanhado de cromatografia de papel.

Nos três processos de vinificação, adicionaram-se ao mosto antes do início da fermentação alcoólica, $50 \mathrm{mg} / \mathrm{L}$ de dióxido de enxofre e $0,20 \mathrm{~g} / \mathrm{L}$ de levedura seca ativa (Saccharomyces cerevisiae). Uma vez concluída a fermentação alcoólica, determinada pela análise do açúcar residual, o vinho foi resfriado a $-4^{\circ} \mathrm{C}$, por dez dias, filtrado com filtro de microfibra de vidro, com porosidade de $8,0 \mu \mathrm{m}$, acrescido de $50 \mathrm{mg} / \mathrm{L}$ de dióxido de enxofre e engarrafado.

As determinações da densidade (DEN), teor alcoólico (AL), acidez total (ACT), acidez volátil (ACV), $\mathrm{pH}$, extrato seco (EXS), açúcares redutores (AÇR), extrato seco reduzido (EXR), relação álcool em peso/extrato seco re- 
duzido (RAE), cinzas (CIZ) e alcalinidade das cinzas (ALC) dos vinhos, foram realizadas através de métodos descritos por Amerine \& Ough (1976). Os polifenóis totais (POL), taninos (TAN), antocianinas (ANT), intensidade de cor (INT) e coloração (COL), foram determinados segundo Ribéreau-Gayon \& Stonestreet $(1965,1966)$.

$\mathrm{O} \mathrm{Ca}, \mathrm{Mg}, \mathrm{Mn}, \mathrm{Fe}, \mathrm{Cu}$ e $\mathrm{Zn}$ foram analisados por absorção atômica, enquanto que o K, Na, Li e Rb por emissão de chama (Perkin-Elmer, 1976). O teor de P foi determinado por colorimetria, com molibdato de amônio (Tedesco et al., 1985). Os compostos voláteis acetato de etila (ACE), metanol (MET), propanol-1 (PRO), metil-2 propanol-1 (M2P), metil-2 + metil-3 butanol-1 (M2M) e a soma dos álcoois superiores (SAS) foram determinados por cromatografia de fase gasosa. Para isso, utilizou-se um aparelho equipado com um detector de ionização de chama e uma coluna de aço inoxidável Carbowax 600, de 3,2 m de comprimento e de $1 / 8$ " de diâmetro interno. $\mathrm{O}$ gás vetor utilizado foi o nitrogênio, na vazão de $30 \mathrm{~mL} / \mathrm{min}$. A temperatura do vaporizador foi de $140^{\circ} \mathrm{C}$, a do forno de $98^{\circ} \mathrm{C}$ e a do detector de $160^{\circ} \mathrm{C}$. A amostra de vinho $(3 \mu \mathrm{L})$ foi injetada diretamente, após ter recebido $10 \%$ do volume de uma solução de metil-4 pentanol-2 a $1 \mathrm{~g} / \mathrm{L}$ como padrão interno (Bertrand, 1975).

Os vinhos foram analisados entre os meses de junho e agosto do mesmo ano em que foram elaborados.

A análise sensorial foi efetuada pelo grupo de degustação da Embrapa-Centro Nacional de Pesquisa de Uva e Vinho (CNPUV). Foram realizadas duas sessões de avaliação, degustando os vinhos às cegas. Utilizou-se uma ficha de degustação com itens referentes à intensidade de cor, tonalidade, intensidade olfativa, qualidade olfativa, aromas indesejáveis, intensidade gustativa, corpo, adstringência, acidez, equilíbrio gustativo, qualidade gustativa, gostos indesejáveis, equilíbrio olfato-gustativo, tipicidade e impressão geral.

O estudo das diferenças dos vinhos em função do sistema de vinificação foi feito através da utilização da análise de componentes principais (Foucart, 1982; Rosier, 1992). Os valores da análise sensorial foram submetidos à análise de variância e ao teste de Tukey.

\section{RESULTADOS E DISCUSSÃO}

Os teores médios e os desvios padrão das 33 variáveis físico-químicas determinadas nos vinhos Cabernet Franc, elaborados por meio da vinificação clássica, da termovinificação e da maceração carbônica, são apresentados na Tabela 1. A composição dos vinhos tintos Cabernet Franc elaborados pelos três processos de vinificação corresponde aos valores encontrados em outros trabalhos (Rizzon, 1987; Rizzon \& Salvador, 1987; Miele et al., 1994).

A análise de componentes principais mostra que os eixos 1, 2 e 3 explicam 31,2\%, 22,0\% e 15,0\%, respectivamente, ou seja, $68,2 \%$ da variação total.

A Fig. 1 corresponde à representação gráfica da projeção dos vinhos no plano representado pelos eixos 1 e 2.

O eixo 1 permite separar os vinhos de maceração carbônica dos de vinificação clássica e de termovinificação. Esses dois últimos processos de vinificação originam vinhos semelhantes em relação à sua constituição química. Portanto, este eixo pode ser considerado como sendo o do processo de vinificação. Considerando a safra, o eixo 2 apresenta maior efeito discriminante quanto aos vinhos de vinificação clássica e de termovinificação. Analiticamente, os vinhos da safra de 1987 foram semelhantes aos da safra de 1990, da mesma maneira que os de 1988 se assemelharam aos de 1989. Diante disso, esse eixo pode ser considerado como o eixo que caracteriza a safra vitícola.

A representação gráfica das variáveis no plano formado pelos eixos 1 e 2 é indicada na Fig. 2.

As variáveis melhor correlacionadas em cada eixo são apresentadas na Tabela 2. As que compõem o eixo 1 pertencem ao grupo dos álcoois superiores, alguns cátions, antocianinas, índices de cor, $\mathrm{pH}$ e acidez total.

Com relação aos álcoois superiores, eles já foram indicados por apresentar efeito discriminante em vinhos de diferentes regiões vitícolas (Marais et al., 1981; Medina \& Van Zeller, 1984; Shinohara, 1984; Rizzon et al., 1987).

Entre os três processos de vinificação, os vinhos de maceração carbônica se diferenciam por apresentar maior concentração de propanol-1 e menores teores de metil-2 propanol-1, metil-2 butanol-1 + metil-3 butanol-1, e, conseqüentemente, menor valor para a soma dos álcoois superiores. A maceração carbônica permitiu a obtenção de mostos mais límpidos, proporcionando fermentação mais lenta e com temperatura mais baixa, diminuindo os teores da soma dos álcoois superiores. O propanol-1 foi exceção, pois os fatores que favoreceram a sua síntese são antagônicos aos que favoreceram a formação dos demais álcoois superiores (Bertrand, 1975). 
$\mathrm{O} \mathrm{Fe}, \mathrm{Li}, \mathrm{Mn}$ e Rb participaram da formação do eixo 1 e contribuíram para a separação dos vinhos. Os teores mais elevados desses minerais nos vinhos de maceração carbônica deveram-se, possivelmente, à presença da ráquis no processo de maceração carbônica e à prensagem da uva.

A coloração, a intensidade de cor e as antocianinas, também mostraram uma participação acentuada na diferenciação dos vinhos. A termovinificação se caracterizou por produzir vinhos com maior intensidade de cor e antocianinas, enquanto que os de maceração carbônica, ao contrário, apre- sentaram teores mais baixos desses pigmentos. Càstino \& Ubigli (1984) já haviam constatado a pouca intensidade de cor do vinho Barbera, elaborado pelo processo de maceração carbônica. Considerando os valores da coloração (I 420/I 520), verificou-se que os vinhos de maceração carbônica apresentaram uma tonalidade mais oxidada que os elaborados pelos processos de termovinificação e clássico.

$\mathrm{O} \mathrm{pH}$ e a acidez total foram outras duas variáveis que se correlacionaram bem com o eixo 1 . Os vinhos de maceração carbônica se diferenciaram dos

TABELA 1. Média e desvio padrão de características analíticas dos vinhos Cabernet Franc, elaborados por meio de três processos de vinificação, nas safras de 1987 a 1990.

\begin{tabular}{|c|c|c|c|}
\hline \multirow[t]{2}{*}{ Variável } & \multicolumn{3}{|c|}{ Processo de vinificação } \\
\hline & Clássico & Termovinificação & Maceração carbônica \\
\hline Densidade $(\mathrm{g} / \mathrm{mL}) 20 / 20^{\circ} \mathrm{C}$ & $0,9951 \pm 0,0014$ & $0,9951 \pm 0,0014$ & $0,9948 \pm 0,0016$ \\
\hline Teor alcoólico $(\% \mathrm{v} / \mathrm{v})$ & $11,20 \pm 0,62$ & $11,09 \pm 0,53$ & $11,03 \pm 0,52$ \\
\hline Acidez total $(\mathrm{meq} / \mathrm{L})$ & $75,5 \pm 2,5$ & $73,0 \pm 3,8$ & $63,0 \pm 9,3$ \\
\hline Acidez volátil (meq/L) & $9,5 \pm 1,0$ & $10,0 \pm 3,8$ & $12,8 \pm 3,3$ \\
\hline $\mathrm{pH}$ & $3,59 \pm 0,08$ & $3,69 \pm 0,12$ & $3,89 \pm 0,16$ \\
\hline Extrato seco $(\mathrm{g} / \mathrm{L})$ & $25,80 \pm 2,89$ & $24,20 \pm 4,30$ & $24,10 \pm 1,24$ \\
\hline Açúcares redutores $(\mathrm{g} / \mathrm{L})$ & $2,88 \pm 0,86$ & $2,31 \pm 0,70$ & $2,37 \pm 0,65$ \\
\hline Extrato seco reduzido $(\mathrm{g} / \mathrm{L})$ & $23,96 \pm 3,65$ & $22,89 \pm 4,40$ & $22,74 \pm 1,38$ \\
\hline Relação álcool em peso/extrato seco reduzido & $3,81 \pm 0,68$ & $3,97 \pm 0,79$ & $3,89 \pm 0,30$ \\
\hline Cinzas $(g / L)$ & $3,03 \pm 0,59$ & $3,15 \pm 0,49$ & $3,53 \pm 0,13$ \\
\hline Alcalinidade das cinzas (meq/L) & $23,60 \pm 6,00$ & $26,30 \pm 5,06$ & $29,00 \pm 3,72$ \\
\hline Polifenóis totais (I 280) & $30,6 \pm 8,7$ & $38,7 \pm 7,5$ & $34,1 \pm 8,3$ \\
\hline Taninos $(\mathrm{g} / \mathrm{L})$ & $1,53 \pm 0,25$ & $1,90 \pm 0,36$ & $1,95 \pm 0,26$ \\
\hline Antocianinas $(\mathrm{mg} / \mathrm{L})$ & $311 \pm 61$ & $418 \pm 37$ & $221 \pm 87$ \\
\hline Intensidade de cor (I $420+$ I 520) & $0,751 \pm 0,310$ & $1,018 \pm 0,338$ & $0,568 \pm 0,197$ \\
\hline Coloração (I 420/I 520) & $0,553 \pm 0,177$ & $0,510 \pm 0,071$ & $0,779 \pm 0,309$ \\
\hline Acetato de etila $(\mathrm{mg} / \mathrm{L})$ & $74,2 \pm 8,8$ & $49,5 \pm 17,2$ & $93,7 \pm 49,1$ \\
\hline Metanol (mg/L) & $173,2 \pm 35,2$ & $92,1 \pm 14,1$ & $94,8 \pm 34,6$ \\
\hline Propanol-1 (mg/L) & $22,7 \pm 6,6$ & $17,2 \pm 4,2$ & $57,5 \pm 24,6$ \\
\hline Metil-2 propanol-1 (mg/L) & $63,1 \pm 11,1$ & $60,0 \pm 8,2$ & $49,3 \pm 17,6$ \\
\hline Metil-2 + metil-3 butanol-1 (mg/L) & $321 \pm 80$ & $342 \pm 71$ & $170 \pm 16$ \\
\hline Soma dos álcoois superiores $(\mathrm{mg} / \mathrm{L})$ & $406 \pm 80$ & $419 \pm 74$ & $269 \pm 5$ \\
\hline $\mathrm{K}(\mathrm{mg} / \mathrm{L})$ & $1203 \pm 181$ & $1414 \pm 234$ & $1529 \pm 149$ \\
\hline $\mathrm{Na}(\mathrm{mg} / \mathrm{L})$ & $11,3 \pm 8,3$ & $9,9 \pm 5,8$ & $11,9 \pm 7,9$ \\
\hline $\mathrm{Ca}(\mathrm{mg} / \mathrm{L})$ & $74,6 \pm 14,9$ & $76,8 \pm 13,2$ & $63,3 \pm 9,3$ \\
\hline $\mathrm{Mg}(\mathrm{mg} / \mathrm{L})$ & $76,4 \pm 13,1$ & $72,8 \pm 7,8$ & $79,8 \pm 8,9$ \\
\hline $\mathrm{Mn}(\mathrm{mg} / \mathrm{L})$ & $2,2 \pm 0,3$ & $2,0 \pm 0,2$ & $3,1 \pm 0,4$ \\
\hline $\mathrm{Fe}(\mathrm{mg} / \mathrm{L})$ & $1,4 \pm 0,3$ & $1,6 \pm 0,2$ & $3,1 \pm 1,1$ \\
\hline $\mathrm{Cu}(\mathrm{mg} / \mathrm{L})$ & $0,8 \pm 0,8$ & $0,8 \pm 0,7$ & $0,4 \pm 0,3$ \\
\hline $\mathrm{Zn}(\mathrm{mg} / \mathrm{L})$ & $0,5 \pm 0,1$ & $0,8 \pm 0,1$ & $0,4 \pm 0,2$ \\
\hline $\operatorname{Li}(\mu \mathrm{g} / \mathrm{L})$ & $2,7 \pm 1,1$ & $2,9 \pm 0,8$ & $6,6 \pm 2,6$ \\
\hline $\mathrm{Rb}(\mathrm{mg} / \mathrm{L})$ & $5,4 \pm 0,8$ & $6,2 \pm 0,7$ & $7,5 \pm 2,2$ \\
\hline $\mathrm{P}(\mathrm{mg} / \mathrm{L})$ & $121 \pm 27$ & $131 \pm 30$ & $144 \pm 55$ \\
\hline
\end{tabular}




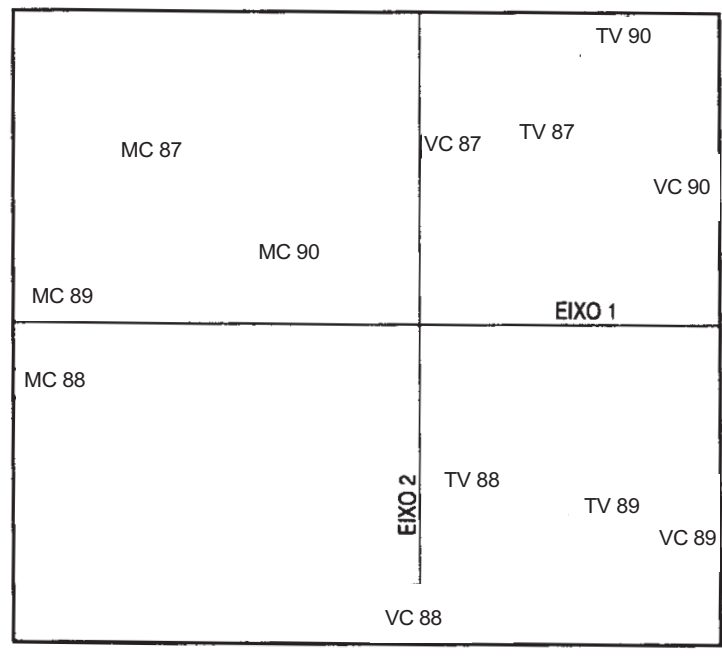

FIG. 1. Projeção dos vinhos sobre o plano formado pelos eixos 1 e 2 . Legenda: 87, 88, 89 e 90 - Safras de 1987, 1988, 1989 e 1990; VC - vinificação clássica; TV - termovinificação; MC - maceração carbônica.

demais pelo $\mathrm{pH}$ mais elevado e acidez total mais baixa. Na fermentação maloláctica, o ácido málico é metabolizado em ácido láctico pela ação das bactérias, na maceração carbônica ele é transformado em álcool etílico pela ação enzimática, provocando uma redução na acidez total (Flanzy et al., 1967; Ribéreau-Gayon et al., 1976; Spagnolli, 1987).

As variáveis melhor correlacionadas e que compõem o eixo 2 (Tabela 2) são as que fazem parte do extrato do vinho, como a relação álcool em peso/extrato seco reduzido, densidade, extrato seco reduzido, alcalinidade das cinzas e extrato seco, e os cátions $\mathrm{Cu}, \mathrm{Ca}$ e $\mathrm{K}$.

Os vinhos elaborados pelo processo de vinificação clássica e de termovinificação de 1988 e de 1989 se diferenciaram dos de 1987 e 1990, por apresentar maior valor da relação álcool em peso/extrato seco reduzido, $\mathrm{Cu}$ e açúcares redutores. As safras de 1988 e de 1989 originaram vinhos mais leves, isto é, com menos extrato seco e extrato seco reduzido. Os vinhos elaborados nas safras de 1987 e de 1990 se caracterizaram por apresentar valores mais elevados de extrato seco, extrato seco reduzido, den-

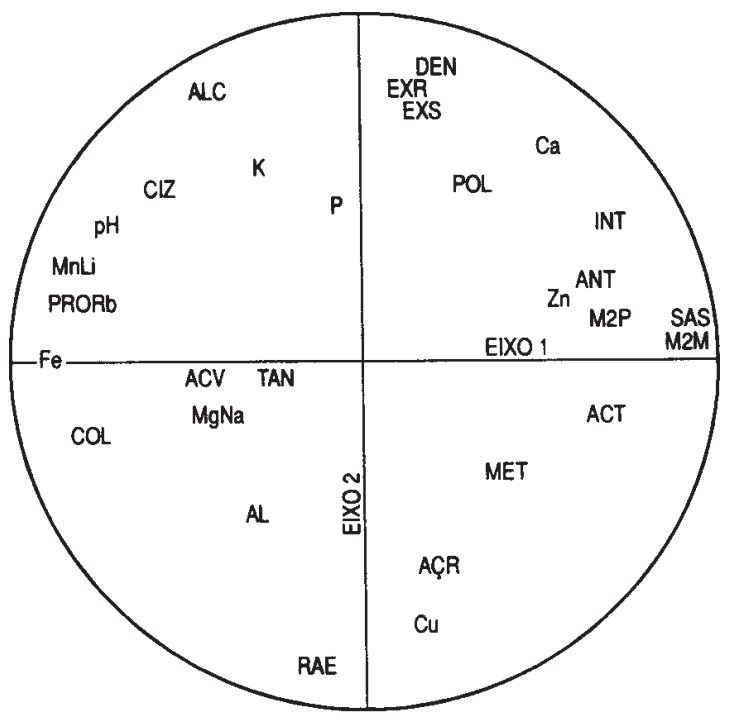

FIG. 2. Círculo das correlações do plano formado pelos eixos 1 e 2. Legenda: DEN - densidade; AL - teor alcoólico; ACT - acidez total; ACV - acidez volátil; pH - pH; EXS - extrato seco; AÇR - açúcares redurores; EXR - extrato seco reduzido; RAE - relação álcool em peso/extrato seco reduzido; CIZ - cinzas; ALC - alcalinidade das cinzas; POL - polifenóis totais; TAN - taninos; ANT - antocianinas; INT - intensidade de cor; COL - coloração; ACE - acetato de etila; MET - metanol; PRO - propanol-1; M2P - metil-2 propanol-1; M2M - metil-2 + metil-3 butanol-1; SAS - soma dos álcoois superiores; K - potássio; Na - sódio; Ca - cálcio; Mg - magnésio; Mn - manganês; Fe - ferro; Cu - cobre; Zn - zinco; Li - lítio; Rb - rubídio; P - fósforo.

sidade, alcalinidade das cinzas, Ca e K. Isso possivelmente ocorreu devido às condições climáticas nessas duas safras, mais favoráveis à maturação da uva.

O eixo 3 é formado por componentes relacionados aos fatores de solo e clima, como o $\mathrm{Mg}$ e $\mathrm{P}$, polifenóis totais e acidez total; é formado, também, pelo acetato de etila, mais relacionado com o processo de vinificação (Tabela 2).

Quanto à análise sensorial, as médias das notas atribuídas pelo grupo de degustação para os vinhos 
TABELA 2. Correlação entre as variáveis e os três principais eixos.

\begin{tabular}{|c|c|c|c|}
\hline \multirow[t]{2}{*}{ Variável } & \multicolumn{3}{|c|}{ Eixo } \\
\hline & 1 & 2 & 3 \\
\hline Densidade $(\mathrm{g} / \mathrm{mL}) 20 / 20^{\circ} \mathrm{C}$ & 0,2188 & $0,9008^{*}$ & 0,2573 \\
\hline Teor alcoólico $(\% \mathrm{v} / \mathrm{v})$ & $-0,2808$ & $-0,4210$ & 0,3247 \\
\hline Acidez total $(\mathrm{meq} / \mathrm{L})$ & $0,6751^{*}$ & $-0,1361$ & $0,6442 *$ \\
\hline Acidez volátil (meq/L) & $-0,4517$ & $-0,0555$ & 0,4850 \\
\hline $\mathrm{pH}$ & $-0,7051^{*}$ & 0,4054 & $-0,1533$ \\
\hline Extrato seco $(\mathrm{g} / \mathrm{L})$ & 0,1795 & $0,7445^{*}$ & 0,3828 \\
\hline Açúcares redutores $(\mathrm{g} / \mathrm{L})$ & 0,1994 & $-0,5859$ & 0,4466 \\
\hline Extrato seco reduzido $(\mathrm{g} / \mathrm{L})$ & 0,1208 & $0,8273 *$ & 0,2526 \\
\hline Relação álcool em peso/extrato seco reduzido & $-0,1550$ & $-0,9028^{*}$ & $-0,1546$ \\
\hline Cinzas $(g / L)$ & $-0,5658$ & 0,5583 & 0,4132 \\
\hline Alcalinidade das cinzas (meq/L) & $-0,4250$ & $0,7975^{*}$ & 0,0041 \\
\hline Polifenóis totais (I 280) & 0,3111 & 0,5579 & $-0,6357^{*}$ \\
\hline Taninos $(g / L)$ & $-0,2459$ & $-0,0566$ & $-0,2194$ \\
\hline Antocianinas $(\mathrm{mg} / \mathrm{L})$ & $0,6466^{*}$ & 0,2542 & $-0,4396$ \\
\hline Intensidade de cor (I $420+$ I 520) & $0,6869^{*}$ & 0,4128 & 0,1366 \\
\hline Coloração (I 420 / I 520) & $-0,7799 *$ & $-0,2182$ & $-0,3899$ \\
\hline Acetato de etila $(\mathrm{mg} / \mathrm{L})$ & $-0,4029$ & $-0,1180$ & $0,7787 *$ \\
\hline Metanol (mg/L) & 0,3849 & $-0,3228$ & 0,2002 \\
\hline Propanol-1 (mg/L) & $-0,8177^{*}$ & 0,2021 & $-0,3025$ \\
\hline Metil-2 propanol-1 (mg/L) & $0,6846^{*}$ & 0,1411 & 0,3967 \\
\hline Metil-2 + metil-3 butanol-1 (mg/L) & $0,8977^{*}$ & 0,0851 & $-0,1475$ \\
\hline Soma dos álcoois superiores $(\mathrm{mg} / \mathrm{L})$ & $0,9041^{*}$ & 0,1617 & $-0,1213$ \\
\hline $\mathrm{K}(\mathrm{mg} / \mathrm{L})$ & $-0,2610$ & $0,6009^{*}$ & $-0,2307$ \\
\hline $\mathrm{Na}(\mathrm{mg} / \mathrm{L})$ & $-0,3769$ & $-0,1142$ & 0,3586 \\
\hline $\mathrm{Ca}(\mathrm{mg} / \mathrm{L})$ & 0,5281 & $0,6639 *$ & 0,1974 \\
\hline $\operatorname{Mg}(\mathrm{mg} / \mathrm{L})$ & $-0,3869$ & $-0,1306$ & $0,7688^{*}$ \\
\hline $\mathrm{Mn}(\mathrm{mg} / \mathrm{L})$ & $-0,8202 *$ & 0,3191 & $-0,0226$ \\
\hline $\mathrm{Fe}(\mathrm{mg} / \mathrm{L})$ & $-0,8711^{*}$ & 0,0534 & 0,0657 \\
\hline $\mathrm{Cu}(\mathrm{mg} / \mathrm{L})$ & 0,1743 & $-0,7753^{*}$ & $-0,0472$ \\
\hline $\mathrm{Zn}(\mathrm{mg} / \mathrm{L})$ & 0,5425 & 0,2263 & $-0,5687$ \\
\hline $\mathrm{Li}(\mu \mathrm{g} / \mathrm{L})$ & $-0,8508^{*}$ & 0,2955 & $-0,1240$ \\
\hline $\mathrm{Rb}(\mathrm{mg} / \mathrm{L})$ & $-0,7435^{*}$ & 0,1816 & $-0,3779$ \\
\hline $\mathrm{P}(\mathrm{mg} / \mathrm{L})$ & $-0,0565$ & 0,4867 & $0,6826^{*}$ \\
\hline
\end{tabular}

*Correlações consideradas importantes.

de vinificação clássica, de maceração carbônica e de termovinificação, estão indicadas na Tabela 3.

Observaram-se diferenças significativas quanto à intensidade de cor, tonalidade, qualidade olfativa, corpo, acidez, equilíbrio gustativo, qualidade gustativa, equilíbrio olfato-gustativo, tipicidade e impressão geral. Do ponto de vista sensorial, os processos de vinificação clássica e de termovinificação originaram vinhos mais parecidos que os de maceração carbônica. Esse fato foi evidenciado an- teriormente pela análise de componentes principais com os resultados das análises físico-químicas dos vinhos.

Quanto ao aroma, as transformações bioquímicas que interferiram na uva e no mosto durante o processo de maceração carbônica originaram vinhos com menor qualidade olfativa.

A maceração carbônica também se distinguiu por apresentar vinhos mais leves, menos estruturados, com menos corpo. Em relação à acidez total, obser- 
TABELA 3. Médias das notas atribuídas, pelo grupo de degustação, aos vinhos Cabernet Franc, elaborados através de três processos de vinificação, durante as safras de 1987 a $1990^{1}$.

\begin{tabular}{lccccc}
\hline Variável & \multicolumn{3}{c}{ Processo de vinificação } & C.V. & Prob. > F \\
\cline { 2 - 4 } & Clássico & Termovinificação & $\begin{array}{c}\text { Maceração } \\
\text { carbônica }\end{array}$ & $(\%)$ & \\
\hline Intensidade de cor & $4,57 \mathrm{~b}$ & $6,02 \mathrm{a}$ & $3,26 \mathrm{c}$ & 21,04 & 0,00001 \\
Tonalidade & $3,86 \mathrm{~b}$ & $2,56 \mathrm{c}$ & $5,46 \mathrm{a}$ & 37,14 & 0,00005 \\
Intensidade olfativa & $4,28 \mathrm{a}$ & $4,43 \mathrm{a}$ & $4,63 \mathrm{a}$ & 20,23 & 0,54151 \\
Qualidade olfativa & $4,19 \mathrm{a}$ & $4,10 \mathrm{a}$ & $3,26 \mathrm{~b}$ & 24,48 & 0,01350 \\
Aromas indesejáveis & $0,59 \mathrm{a}$ & $0,84 \mathrm{a}$ & $1,11 \mathrm{a}$ & 129,53 & 0,57875 \\
Intensidade gustativa & $4,55 \mathrm{a}$ & $4,66 \mathrm{a}$ & $4,19 \mathrm{a}$ & 16,45 & 0,17101 \\
Corpo & $3,94 \mathrm{a}$ & $3,97 \mathrm{a}$ & $3,29 \mathrm{~b}$ & 16,17 & 0,00398 \\
Adstringência & $2,81 \mathrm{a}$ & $2,93 \mathrm{a}$ & $2,49 \mathrm{a}$ & 69,42 & 0,79703 \\
Acidez & $3,73 \mathrm{ab}$ & $4,03 \mathrm{a}$ & $3,22 \mathrm{~b}$ & 22,48 & 0,02595 \\
Equilíbrio gustativo & $3,94 \mathrm{a}$ & $4,11 \mathrm{a}$ & $3,19 \mathrm{~b}$ & 17,70 & 0,00090 \\
Qualidade gustativa & $4,06 \mathrm{a}$ & $4,32 \mathrm{a}$ & $3,19 \mathrm{~b}$ & 19,18 & 0,00043 \\
Gostos indesejáveis & $0,58 \mathrm{a}$ & $1,85 \mathrm{a}$ & $1,36 \mathrm{a}$ & 146,56 & 0,26793 \\
Equilíbrio olfato-gustativo & $4,24 \mathrm{a}$ & $4,37 \mathrm{a}$ & $3,28 \mathrm{~b}$ & 19,86 & 0,00069 \\
Tipicidade & $4,26 \mathrm{a}$ & $4,43 \mathrm{a}$ & $2,96 \mathrm{~b}$ & 23,20 & 0,00014 \\
Impressão geral & $5,08 \mathrm{a}$ & $5,29 \mathrm{a}$ & $3,62 \mathrm{~b}$ & 17,69 & 0,00001 \\
\hline
\end{tabular}

${ }^{1}$ Médias seguidas por letras distintas, na linha, diferem entre si pelo teste de Tukey a $5 \%$ de probabilidade.

vou-se diferença significativa entre o vinho de termovinificação, considerado o mais ácido na avaliação sensorial, e o de maceração carbônica, julgado menos ácido.

Quanto ao gosto, o vinho de maceração carbônica se diferenciou por apresentar notas significativamente mais baixas no que se refere ao equilíbrio gustativo, equilíbrio olfato-gustativo e qualidade gustativa. Os vinhos de termovinificação e de vinificação clássica tiveram melhor impressão geral.

\section{CONCLUSÕES}

1. A análise de componentes principais permite separar os vinhos de maceração carbônica dos elaborados por termovinificação e por vinificação clássica.

2. A termovinificação possibilita a obtenção de vinhos tintos com mais cor e extrato.

3. A maceração carbônica origina vinhos mais leves e com menor intensidade de cor e acidez.

4. O vinho de maceração carbônica se diferencia por apresentar notas mais baixas em equilíbrio gustativo, equilíbrio olfato-gustativo e qualidade gustativa.

5. Os vinhos de termovinificação e de vinificação clássica apresentam melhor impressão geral.

\section{REFERÊNCIAS}

AMERINE, M.A.; OUGH, C.S. Análisis de vinos y mostos. Zaragoza: Acribia, 1976. 158p.

ANDRÉ, P.; BÉNARD, P.; CHAMBROY, Y.; FLANZY, C.; JOURET, C. Méthode de vinification par macération carbonique. II. La production d'alcool en vinification par macération carbonique. Annales de Technologie Agricole, Paris, v.16, n.2, p.117-123, 1967.

ARFELLI, G. La tecnica di vinificazione per macerazione carbonica. Vignevini, Bologna, v.17, n.1/2, p.33-38, 1990.

BERTRAND, A. Recherches sur l'analyse des vins par chromatographie en phase gazeuse. Talence: Université de Bordeaux II, 1975. 291p. Thèse de Doctorat.

CÀSTINO, M. Macerazione carbonica: ricerca, risultati, tecnologia. L'Enotecnico, Milano, v.20, n.10, p.865-868, 1984.

Pesq. agropec. bras., Brasília, v.34, n.7, p.1285-1293, jul. 1999 
CÀSTINO, M.; UBIGLI, M. Prove di macerazione carbonica com uve Barbera. Vini d'Italia, Brescia, v.26, n.6, p.7-23, 1984

FLANZY, C.; ANDRÉ, P.; FLANZY, M.; CHAMBROY, $Y$. Variations quantitatives des acides organiques stables, non cétoniques, non volatils, dans les baies de raisin placées en anaérobiose carbonique. I. Influence de la température. Annales de Technologie Agricole, Paris, v.16, n.1, p.27-34, 1967.

FLANZY, C.; BÉNARD, P.; AUBERT, S. Méthode de vinification par macération carbonique. IV. Influence de la température et de la durée de macération carbonique sur la qualité des vins secs élaborés à partir de "Grenache Noir". Annales de Technologie Agricole, Paris, v.19, n.1, p.29-40, 1970

FOUCART, T. Analyse factorielle. Programmation sur micro-ordinateurs. Paris: Masson, 1982. 245p.

MARAIS, J.; VAN ROOYEN, P.C.; DU PLESSIS, C.S. Classification of white cultivar wines by origin using volatile aroma components. South African Journal for Enology and Viticulture, Stellenbosch, v.2, n.2, p.45-49, 1981

MEDINA, B.; VAN ZELLER, A.L. Différenciation des vins de trois régions de France. Connaissance de la Vigne et du Vin, Talence, v.18, n.4, p.225-235, 1984

MIELE, A.; RIZZON, L.A.; ZANUZ, M.C. Avaliação nacional de vinhos - safra 1993. Boletim da Sociedade Brasileira de Ciência e Tecnologia de Alimentos, Campinas, v.28, n.2, p.161-169, 1994.

PERKIN-ELMER. Analytical methods for atomic absorption spectrophotometry. Norwalk: PerkinElmer, 1976. 432p.

PERUZZI, E.J. La termovinificación. In: SIMPÓSIO LATINO-AMERICANO DE VITICULTURA E ENOLOGIA, 3., CONGRESSO BRASILEIRO DE VITICULTURA E ENOLOGIA, 6., JORNADA LATINO-AMERICANA DE VITICULTURA E ENOLOGIA, 4., 1990, Bento Gonçalves e Garibaldi. Anais... Bento Gonçalves: EmbrapaCNPUV/ABTEV/OIV, 1991. p.97-104.

RIBÉREAU-GAYON, P.; GLORIES, Y. La tipicizzazione dei vini rossi: caratteri chimici ed organolettici. L'Enotecnico, Milano, v.22, n.5, p.545-552, 1986.
RIBÉREAU-GAYON， J.; PEYNAUD, E.; RIBÉREAU-GAYON, P.; SUDRAUD, P. Sciences et techniques du vin. Paris: Dunod, 1976. v.3, 719p.

RIBÉREAU-GAYON, P.; STONESTREET, E. Dosage des tanins du vin rouge et détermination de leur structure. Chimie Analytique, Paris, v.48, n.4, p.188-196, 1966.

RIBÉREAU-GAYON, P.; STONESTREET, E. Le dosage des anthocyanes dans les vins rouges. Bulletin de la Societé Chimique de France, Paris, v.9, p.2649-2652, 1965.

RIZZON, L.A. Composição química dos vinhos da Microrregião Homogênea Vinicultora de Caxias do Sul (MRH 311) - Compostos voláteis. Bento Gonçalves: Embrapa-CNPUV, 1987. 4p. (EmbrapaCNPUV. Comunicado técnico, 5).

RIZZON, L.A.; SALVADOR, M.B.G. Teores de cátions dos vinhos da Microrregião Homogênea Vinicultora de Caxias do Sul (MRH 311). Bento Gonçalves: Embrapa-CNPUV, 1987. 4p. (EmbrapaCNPUV. Comunicado técnico, 4).

RIZZON, L.A.; SALVADOR, M.B.G.; GATTO, N.M Características analíticas dos vinhos brancos de quatro municípios da Microrregião Homogênea Vinicultora de Caxias do Sul (MRH 311). In: SIMPÓSIO LATINO-AMERICANO DE ENOLOGIA E VITICULTURA, 2., JORNADA LATINO-AMERICANA DE VITICULTURA E ENOLOGIA, 2., SIMPÓSIO ANUAL DE VITIVINICULTURA, 2., 1987, Garibaldi e Bento Gonçalves. Anais... Bento Gonçalves: ABTEV, 1987. p.224-230.

ROSIER, J.P. Interprétation des caractères analytiques et sensoriels des vins blancs de la région des Graves en fonction de certains facteurs culturaux de la vigne. Talence: Université de Bordeaux II, 1992. 254p. Thèse de Doctorat.

SHINOHARA, T. L'importance des substances volatiles du vin. Formation et effets sur la qualité. Bulletin de l'O.I.V., Paris, v.57, n.641/642, p.606-618, 1984

SPAGNOLLI, F. Vini novelli da macerazione carbonica Vini d'Italia, Brescia, v.29, n.6, p.27-32, 1987.

TEDESCO, M.J.; VOLKWEISS, J.J.; BOHNEN, H. Análise de solo, plantas e outros materiais. Porto Alegre: Departamento de Solos, UFRGS, 1985. 189p. (Boletim técnico, 5).

UBIGLI, M. Considerazioni su alcune particolarità dei vini novelli. Vini d'Italia, Brescia, v.28, n.5, p.9-18, 1986. 
UBIGLI, M. Tecniche di vinificazione in rosso. Vini d'Italia, Brescia, v.30, n.5, p.9-16, 1988.

USSEGLIO-TOMASSET, L. Interventi e trattamenti nella produzione dei vini rosati per mezzo della macerazione carbonica. Vini d'Italia, Brescia, v.28, n.3, p.65-70, 1986.

VERSINI, G.; DALLA SERRA, A.; PELLEGRINI, R. Contributo alla conoscenza dell'aroma dei vini da macerazione carbonica. L'Enotecnico, Milano, v. 20, n.10, p.871-878, 1984.

VILLA, D. Influenza della macerazione carbonica in fase gassosa. Vini d'Italia, Brescia, v.30, n.3, p.23-34, 1988.

WAGENER, G.W.W. The effect of different thermovinification systems on red wine quality. American Journal of Enology and Viticulture Lockeford, v.32, n.3, p.179-184, 1981. 